\title{
Determination of N-nitrosodimethylamine in drinking water by UPLC-MS/MS
}

\author{
Wanfeng Wang ${ }^{1}$, Jianying $\mathrm{Hu}^{2}$, Jianwei $\mathrm{Yu}^{1}$, Min Yang ${ }^{1, *}$ \\ 1. State Key Lab of Environmental Aquatic Chemistry, Research Center for Eco-Environmental Sciences, \\ Chinese Academy of Sciences, Beijing 100085, China.E-mail: fengmanlou2005@gmail.com \\ 2. College of Environmental Science, Peking University, Beijing 100871, China
}

Received 09 December 2009; revised 04 February 2010; accepted 23 February 2010

\begin{abstract}
The method for detecting N-nitrosodimethylamine (NDMA) in drinking water using ultra performance liquid chromatography (UPLC) coupled with tandem mass spectrometry (MS/MS) was improved by optimizing the clean-up procedure to remove the matrix interference in pretreatment process, and was then applied to a survey of NDMA in both raw and finished water samples from five water treatment plants in South China. The NDMA concentrations ranged from 4.7 to $15.1 \mathrm{ng} / \mathrm{L}$ in raw water samples, and from 4.68 to $46.9 \mathrm{ng} / \mathrm{L}$ in finished water. The NDMA concentration in raw water was found to be related with nitrite concentration, and during the treatment, the NDMA concentration increased following ozonation but decreased after subsequent activated carbon treatment.
\end{abstract}

Key words: drinking water; N-nitrosodimethylamine; UPLC-MS/MS; the matrix interference

DOI: $10.1016 /$ S1001-0742(09)60281-3

\section{Introduction}

N-Nitrosodimethylamine (NDMA) is one of the family members of extremely potent carcinogens, teratogens, mutagens known as N-nitrosamines (IARC, 1978), which was estimated to have an excess lifetime cancer risk of $10^{-6}$ at a concentration of $0.7 \mathrm{ng} / \mathrm{L}$ in drinking water by the US Environmental Protection Agency (US EPA, 2009). Because of its high carcinogenic potency, NDMA has become one of the most focused DBPs in drinking water industry since it was first detected as a new disinfection byproduct in drinking water in Ontario, Canada in 1989 (Jobb et al., 1992). It is now listed among the Unregulated Contaminant Monitoring Rule2 (UCMR2) (US EPA, 2006). Although the maximum contaminant level (MCL) for NDMA in drinking water has not yet been established in the USA, limits have been set at $10 \mathrm{ng} / \mathrm{L}$ in California (OMOE, 2003) and at $9 \mathrm{ng} / \mathrm{L}$ in Ontario (SDWA, 2002).

The occurrence of NDMA in drinking water treatment processes has been investigated throughout Canada and the USA, and NDMA was found to be existed with the highest concentration of $100 \mathrm{ng} / \mathrm{L}$ in some drinking water distribution systems in Alberta of Canada (Barrett et al., 2003), and $30 \mathrm{ng} / \mathrm{L}$ in twenty-one finished water samples in USA (Charrois et al., 2007). The NDMA concentration in Japan is relatively low: the highest concentration was 10 $\mathrm{ng} / \mathrm{L}$ in five plants of twenty-one drinking water treatment plants (DWTPs) (Mari et al., 2009). Up to now, in China, there is no report regarding the occurrence of NDMA in drinking water systems. However, it is easy to speculate that NDMA should exist in some urban water systems, considering the fact that source water pollution problem is still serious and chloramine disinfection is adopted in many waterworks.

Due to the low concentration of NDMA in drinking water, a sensitive and specific analytical method of NDMA in drinking water is necessary. With the rapid development of analytical methods, some high resolution instruments like GC-MS/MS, GC-HRMS and LC/MS/MS combined with sample pre-concentration method has been applied to the analysis (William et al., 2003; Mari et al., 2009). Currently both liquid-liquid and solid-phase extraction (SPE) methods have been utilized for the extraction of NDMA from water samples (Charrosis et al., 2004; US EPA, 2004). Liquid-liquid extraction (LLE) required the use of large organic solvents and the processes were laborintensive and time-consuming since NDMA is hydrophilic, polar compound. Compared with LLE for sample preparation, SPE has the advantages of shorter processing time and less solvent requirement. But the matrix interference could not be removed easily in analyzing NDMA by SPE-LC-MS/MS. Therefore, in this study, the clean-up procedure was optimized to remove the matrix interference during the analysis of NDMA using an UPLC-MS/MS system. A survey of NDMA in both raw water and finished water samples from five waterworks in South China was conducted using the improved method. This study will provide valuable information regarding the occurrence of NDMA in drinking water in China.

\footnotetext{
* Corresponding author. E-mail: yangmin@ $@$ rcees.ac.cn
} 


\section{Materials and methods}

\subsection{Chemicals and materials}

Standard solution of NDMA $(200 \mu \mathrm{g} / \mathrm{mL})$ and isotopically labeled standard [6- $\left.\mathrm{H}_{2}\right]$ NDMA (NDMA-d $\mathrm{d}_{6}$, $0.1 \mathrm{~g})$ were obtained from Supelco (USA). Methanol, dichloromethane, diethylether, acetonitrile and hexane of HPLC grade, were obtained from Fisher Chemical Co., (USA). Sodium bicarbonate was obtained from Beijing Chemical Co., (China) and ammonium bicarbonate from Fluka (USA). Solid phase extraction cartridges (Sep-Pak ${ }^{\circledR}$ plus AC-2, $400 \mathrm{mg}$ and Sep-Pak ${ }^{\circledR}$ Vac florisil, $1 \mathrm{~g} / 6 \mathrm{~mL}$ ) were obtained from Waters (Milford, USA) and glass fiber pads $(\mathrm{GF} / \mathrm{C}, 1.2 \mu \mathrm{m})$ were obtained from Whatman Co. (Maidstone, UK). Stock solutions $(10 \mathrm{mg} / \mathrm{L}$ in methanol) for all standard substances were prepared, and stored at $20^{\circ} \mathrm{C}$.

\subsection{UPLC-MS/MS analysis.}

Separation was performed on an ACQUITY UPLC system with a BEH C18 column $(2.1 \mathrm{~mm} \times 150 \mathrm{~mm}$ i.d., 1.7 $\mu \mathrm{m}$; Waters, USA). The mobile phase was composed of 10 $\mathrm{mmol} / \mathrm{L}$ ammonium bicarbonate aqueous solution and acetonitrile. The ratio of solvent acetonitrile was changed as follows: increased from $5 \%$ to $55 \%$ from 0 to $3.5 \mathrm{~min}$, then increased to $95 \%$ over $0.35 \mathrm{~min}$, maintained at $95 \%$ for 2.2 $\mathrm{min}$, and returned back to $5 \%$ over $0.35 \mathrm{~min}$, followed by a 2 min re-equilibration prior to the next sample injection. The flow rate was $0.2 \mathrm{~mL} / \mathrm{min}$ for all stages and the sample injection volume was $20 \mu \mathrm{L}$. Source temperature, desolvation temperature, the rate of desolvation gas, and the cone gas are $110^{\circ} \mathrm{C}, 350^{\circ} \mathrm{C}, 850 \mathrm{~L} / \mathrm{hr}$, and $50 \mathrm{~L} / \mathrm{hr}$, respectively. Detection was performed using an ACQUITY TQD tandem mass spectrometer (Waters, USA) operated in the electrospray ionization (ESI) positive-ion mode. The MRM transitions were $m / z, 74.9 / 43.1$ and $m / z$ 74.9/57.9 for NDMA and $m / z$ 81.0/46.0 for NDMA-d 6 .

\subsection{Sample collection and preparation}

Samples were collected from five waterworks, which were all supplied with inland river water, in South China in March 2009. The water quality parameters of samples are shown in Table 1. Plants A and B adopt the conventional treatment process including coagulation, sedimentation and sand filtration. Plants C, D and E adopt ozone-BAC (biological activated carbon) in addition to the conventional process. Of the five waterworks, only plant A adopts pre-chlorination $(2 \mathrm{mg} / \mathrm{L})$. Samples of raw water and finished water were collected from plants C, D and E, and samples of each major treatment steps were collected from plants A and B.

Sodium thiosulfate $(100 \mathrm{mg} / 500 \mathrm{~mL})$ was added to the finished water samples to quench chlorine residue, followed by filtration with glass fiber pads $(1.2 \mu \mathrm{m}$, Whatman $\mathrm{GF} / \mathrm{C})$. After filtration, water samples $(500 \mathrm{~mL})$ were basified to $\mathrm{pH} 8.0$ using sodium bicarbonate and added 20 $\mathrm{ng} / \mathrm{L}$ of surrogate standard $\left(\mathrm{NDMA}-\mathrm{d}_{6}\right)$ and then extracted with two activated carbon cartridges in series at a flow rate of $3-5 \mathrm{~mL} / \mathrm{min}$ under vacuum, which were previously conditioned with $20 \mathrm{~mL}$ of dichloromethane/diethylether $(50: 50, V / V)$, followed in sequence by $20 \mathrm{~mL}$ of methanol and $20 \mathrm{~mL}$ of pure water. The cartridges were then dried under a slow flow of nitrogen and eluted with $10 \mathrm{~mL}$ of dichloromethane/diethylether solution $(50: 50, \mathrm{~V} / \mathrm{V})$ at a flow rate of 2 to $3 \mathrm{~mL} / \mathrm{min}$. The eluent was then purified by passing through a florisil cartridge, which was rinsed with $20 \mathrm{~mL}$ methanol and then preconditioned with $10 \mathrm{~mL}$ of hexane and $10 \mathrm{~mL}$ dichloromethane/diethylether (50:50, $V / V)$ in series. The eluate was concentrated to around $50 \mu \mathrm{L}$ residues, which was then diluted to $200 \mu \mathrm{L}$ with dichloromethane for UPLC-MS/MS analysis.

\subsection{Method detection limit (MDL) and recovery}

The average absolute recovery rates of NDMA in ultrapure water, river water, and finished water samples were $65 \%, 62 \%$, and $61 \%$, respectively (number of replicates, $n=3$ ) (Table 2). The relative recovery obtained using NDMA-d 6 ranged from $96 \%$ to $108 \%$. The MDL for NDMA was calculated to be $1.2 \mathrm{ng} / \mathrm{L}$ based on a signal-noise ratio of 3:1 using standard solutions in the SIM mode, according to the regulation of the limits of quantification (LOQ)/the method detecting limits (MDL) ratio of 3.3:1 regulated by the International Union of Pure and Applied Chemistry (IUPAC), and the LOQ for NDMA was 3.96 ng/L.

Table 2 Recovery of NDMA in pure, river, and drinking water

\begin{tabular}{llll}
\hline & $\begin{array}{l}\text { NDMA } \\
\text { concentration } \\
(\mathrm{ng} / \mathrm{L})\end{array}$ & $\begin{array}{l}\text { Absolute } \\
\text { recovery } \\
(\%)^{\mathrm{a}}\end{array}$ & $\begin{array}{l}\text { Relative } \\
\text { recovery } \\
(\%)^{\mathrm{b}}\end{array}$ \\
\hline $\begin{array}{l}\text { Ultrapure water } \\
\text { River water }\end{array}$ & 20 & $65(10.2)$ & $108(13)$ \\
Finished water & 20 & $62(4.7)$ & $96(6.2)$ \\
\hline
\end{tabular}

${ }^{a}$ Values shown in parenthesis are relative standard deviation; ${ }^{\mathrm{b}}$ recovery adjusted relative to NDMA-d 6 .

Table 1 Water quality parameters for water samples from drinking water treatment plants (DWTPs)

\begin{tabular}{|c|c|c|c|c|c|c|c|}
\hline \multirow[t]{2}{*}{ DWTPs } & \multicolumn{2}{|c|}{$\mathrm{NH}_{3}-\mathrm{N}(\mathrm{mg} / \mathrm{L})$} & \multicolumn{2}{|c|}{$\mathrm{COD}(\mathrm{mg} / \mathrm{L})$} & \multicolumn{2}{|c|}{$\mathrm{NO}_{2}{ }^{-}-\mathrm{N}(\mathrm{mg} / \mathrm{L})$} & \multirow{2}{*}{$\begin{array}{l}\mathrm{Cl}_{2}(\mathrm{mg} / \mathrm{L}) \\
\mathrm{FW}\end{array}$} \\
\hline & RW & FW & RW & FW & RW & FW & \\
\hline A & 0.67 & 1.08 & 5.92 & 3.76 & 0.227 & $<0.001$ & 1.8 \\
\hline B & 0.2 & 0.21 & 2.3 & 1.5 & 0.022 & $<0.001$ & 1.35 \\
\hline $\mathrm{C}$ & 2.33 & $<0.02$ & 7.03 & 1.93 & 0.11 & $<0.001$ & 1.0 \\
\hline $\mathrm{D}$ & 2.54 & - & - & - & 0.104 & $<0.003$ & 0.55 \\
\hline $\mathrm{E}$ & 2.19 & 0.46 & 5.04 & 1.87 & 0.1 & $<0.001$ & 0.56 \\
\hline
\end{tabular}

RW: raw water; FW: finished water.

-: no detection. 

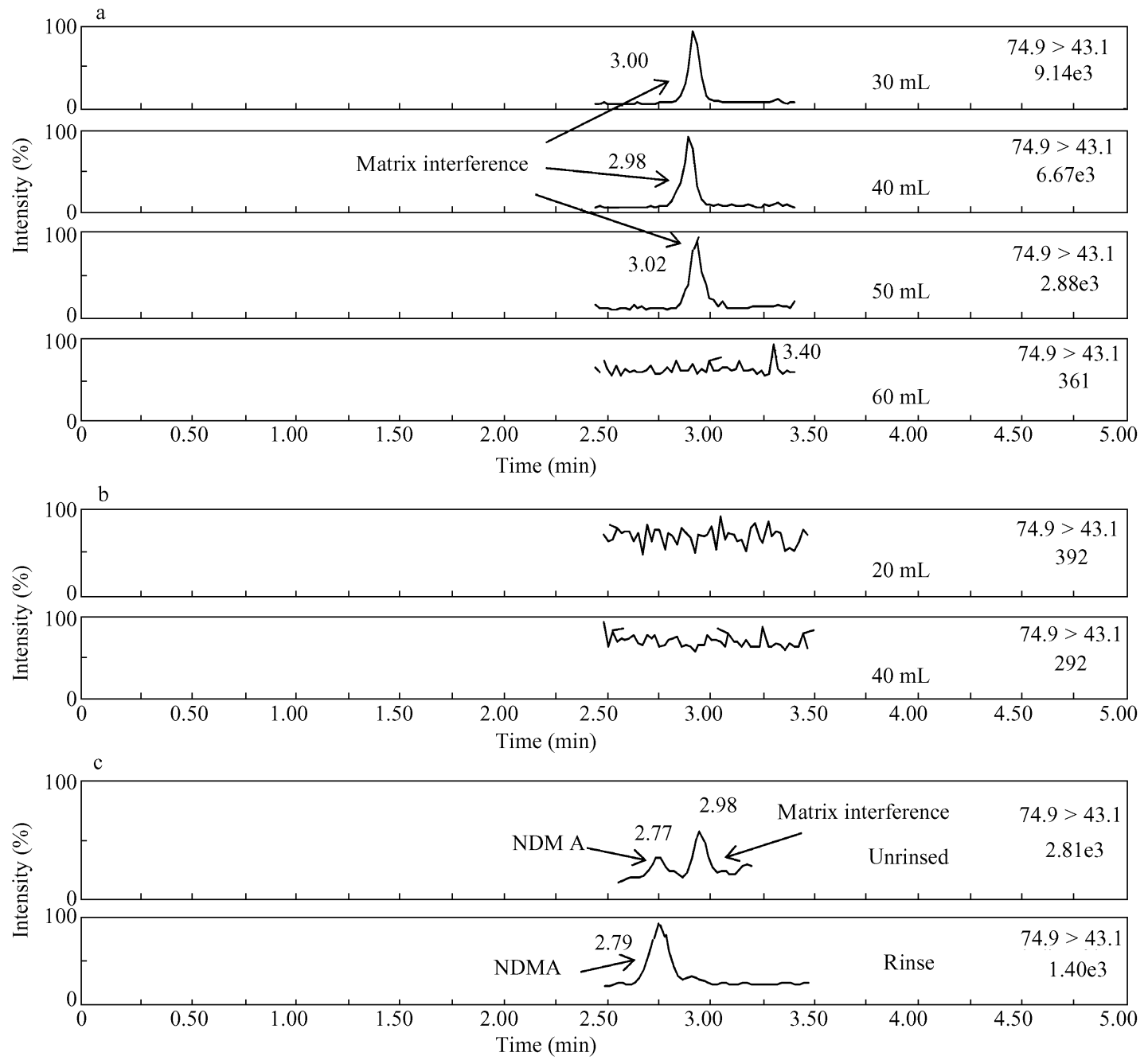

Fig. 1 Optimization of sample preparation. (a) chromatograms of rinsed florisil by dichloromethane/diethylether (50:50, V/V); (b) chromatograms of rinsed florisil by methanol; (c) comparison between rinsed and unrinsed water samples.

\section{Results and discussion}

\subsection{Optimization of sample preparation}

The florisil cartridge was reported to be effective in removing the matrix interference in water samples (Mari et al., 2009). However, we found that some materials released from florisil cartridges could disturb the NDMA detection, leading to the overestimation of NDMA concentration, even varying with different batches. In order to remove the matrix interference, different solvents were tried for rinsing the florisil cartridges. The results are shown in Fig. 1. If the dichloromethane/diethylether $(50: 50, \mathrm{~V} / \mathrm{V})$ solution was used, a volume of $60 \mathrm{~mL}$ was required to completely remove the matrix interference released from florisil cartridges (Fig. 1a). However, methanol was more effective, which only required $20 \mathrm{~mL}$ to completely remove the matrix interference (Fig. 1b). Figure 1c compares the chromatograms acquired with and without methanol rinsing. It is clear that the NDMA peak without the matrix interference was obtained through methanol rinsing.

\subsection{Selection of mobile phase}

The optimal UPLC-MS/MS conditions are important for the unequivocal identification of NDMA at very low levels in environmental samples. Since the ESI is largely dependent on the solvent conditions, the mobile phase and the additive were investigated. In comparison with acetonitrile/water containing $10 \mathrm{mmol} / \mathrm{L}$ ammonium bicarbonate, the mobile phase of acetonitrile/water containing $0.1 \%$ formic acid showed a $33 \%$ increase in the signal intensity. However, the matrix interference released from florisil cartridge could not be eliminated when the latter mobile phase was used for analyzing environmental samples. Thus, acetonitrile/water containing $10 \mathrm{mmol} / \mathrm{L}$ ammonium bicarbonate was selected as mobile phase.

\subsection{Analysis of NDMA in waterworks}

NDMA was detected in both raw water and finished water samples from the five waterworks as listed in Table 3. Figure 2 shows the typical LC-MS/MS chromatograms obtained for raw water, sedimentation effluent, filtration 

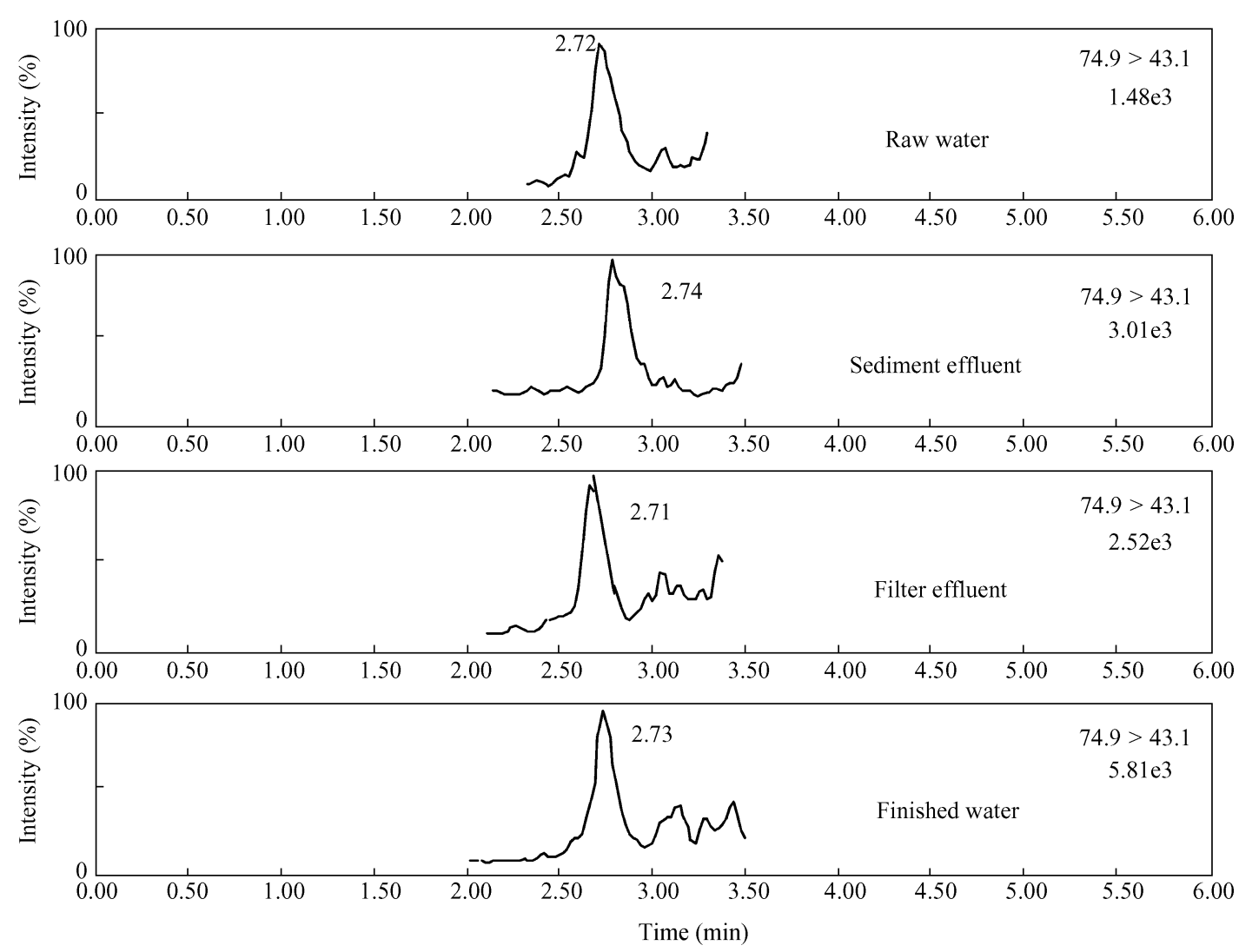

Fig. 2 LC-MS/MS chromatograms of NDMA in water samples from plant A.

effluent, and finished water samples from plant A. The NDMA concentrations in raw water and finished water samples ranged from 4.7 to $15.1 \mathrm{ng} / \mathrm{L}$, and from 4.68 to $46.9 \mathrm{ng} / \mathrm{L}$, respectively, which were comparable to reported results. The concentrations of NDMA in raw water and finished water were $0-2.6 \mathrm{ng} / \mathrm{L}$ and $10 \mathrm{ng} / \mathrm{L}$, respectively, in Japan (Mari et al., 2009), 8-9.4 ng/L and 24-30 ng/L in the United States (Barrett et al., 2003), and as high as 66-100 ng/L of NDMA was detected in drinking water distribution systems in Canada (Charrois and Hrudey, 2007). In plant $E$, the NDMA concentration increased after ozonation, which is also reported previously (Mari et al., 2009; Carles et al., 2008). Among the five waterworks, plant A shows the highest NDMA concentrations in each step. Table 3 also shows that prechlorination could produce significant amount of NDMA in plant A. The NDMA concentrations were very different between plant $\mathrm{A}$ and plant B, although they adopt the same water treatment process, showing that the water quality is an important factor for NDMA formation. The COD and ammonia

Table 3 NDMA concentration in water samples from waterworks

\begin{tabular}{llllll}
\hline DWTPs & \multicolumn{5}{l}{ NDMA concentration $(\mathrm{ng} / \mathrm{L})$} \\
\cline { 2 - 6 } & RW & SE & OE & FE & FW \\
\hline A & 15.1 & 28.8 & - & 22.6 & 46.9 \\
B & 5.12 & 6.61 & - & 4.69 & 5.97 \\
C & 8.9 & nd & nd & nd & 5.8 \\
D & 8.1 & nd & nd & nd & nd \\
E & 4.7 & nd & 14.3 & nd & 4.48 \\
\hline
\end{tabular}

SE: sedimentation effluent; OE: ozonation effluent; FE: filtration effluent. nd: no detection ; -: no process in the waterworks. values of raw water (Table 1) showed that all of the source waters were heavily polluted except for plant B. Especially for plant A, its water intake is located downstream of a river that was contaminated by the discharging of industrial and domestic wastewater, and therefore leading to high concentrations of COD $(5.92 \mathrm{mg} / \mathrm{L})$, ammonia $(0.67 \mathrm{mg} / \mathrm{L})$ and nitrite $(0.227 \mathrm{mg} / \mathrm{L})$, which may be the reason for high NDMA concentration in the raw water. The low NDMA level for plant B might be attributed to its relatively good water quality. The correlations between the water quality indices including total organic carbon (TOC), ultraviolet absorbance, etc. and NDMA concentration were analyzed in previous publications (Zhao et al., 2008; Mari et al., 2009). However, no clear relationship was obtained between the NDMA concentration in the finished water samples and the concentrations of water quality indices in raw water samples. It is interesting that a good relationship was observed between nitrite concentrations and NDMA concentrations in raw water samples (Fig. 3). However, the values of other parameters (residual chlorine, ammonia, COD) have no relationship with NDMA concentrations in both raw water and finished water samples.

On the other hand, the relatively low NDMA concentrations in plants $\mathrm{C}, \mathrm{D}$ and $\mathrm{E}$ might be attributed to the adoption of ozone-BAC process. It is obvious in plant $\mathrm{E}$ that after ozonation, the NDMA concentration increased from 4.7 to $14.3 \mathrm{ng} / \mathrm{L}$ as shown in Table 3, but it decreased markedly (from 14.3 to $4.48 \mathrm{ng} / \mathrm{L}$ ) after activated carbon filtration treatment with a removal of more than $68 \%$. The removal was in accordance with the results previously 


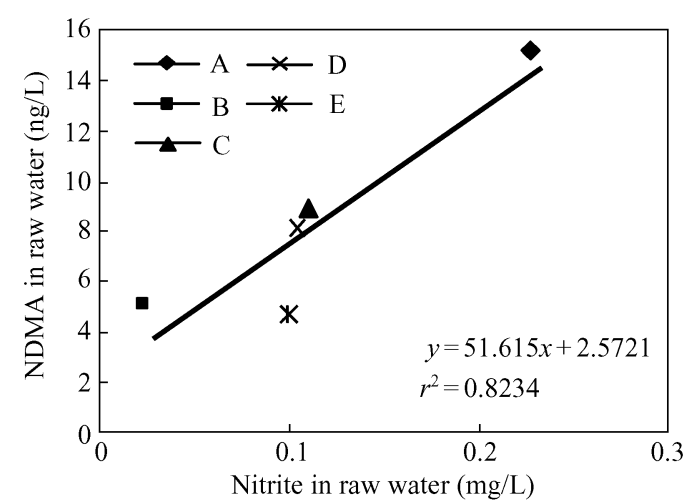

Fig. 3 Correlation between NDMA formation and the water quality.

reported (Mari et al., 2009; Carles et al., 2008).

\section{Conclusions}

Methanol can be considered an effective solvent to remove the matrix interference from florisil cartridges in analyzing NDMA in water samples. A survey on five waterworks in South China showed that all the five raw water samples contained NDMA (4.7-15.1 ng/L), which was related with the nitrite concentrations in raw water. Among the five waterworks, only plant A showed a significant increase of NDMA in finished water. The relatively low NDMA concentrations in other plants might be attributed to the adoption of ozone-BAC process or relatively good raw water quality. This primary study regarding the occurrence of NDMA in drinking water in China could provide the first information on the potential risk of NDMA from waterworks in China.

\section{Acknowledgments}

This work was supported by the National Special Funding Project for Water Pollution Control and Management of China (No. 2009ZX07419-001, 2008ZX07421-004), the Chinese Academy of Sciences Major Projects of Knowledge Innovation Program (No. kzcx-yw-06-02), and the Special Co-construction Project of Beijing Municipal Commission of Education.

\section{References}

Barrett S, Hwang C, Guo Y C, Andrews S A, Valentine R, 2003. Occurrence of NDMA in drinking water: North American survey, 2001-2002. Proceedings of American Waterworks Association Annual Conference and Exhibition, Anaheim, CA, USA. 15-19 June.

Carles P, Óscar P, Francesc V, Josep R, Josep C, 2008. Analysis of nitrosamines in water by automated SPE and isotope dilution GC/HRMS-occurrence in the different steps of a drinking water treatment plant, and in chlorinated samples from a reservoir and a sewage treatment plant effluent. Talanta, 76: 906-913.

Charrois J W A, Arend M W, Froese K F, Hrudey S E, 2004. Detecting N-nitrosamines in drinking water at nanogram per liter levels using ammonia positive chemical ionization. Environmental Science and Technology, 38(18): 48354841.

Charrois J W A, Boyd J M, Froese K L, Hrudey S E, 2007. Occurrence of N-nitrosamines in Alberta public drinking-water distribution systems. Environmental Engineer Science, 6: 103-114.

Charrois J W A, Hrudey S E, 2007. Breakpoint chlorination and free-chlorine contact time: Implication for drinking water $\mathrm{N}$-nitrosodimethylamine concentrations. Water Research, 41: 674-682.

SDWA (Safe Drinking Water Act), 2002. Ontario Regulation 169/03, Schedule2. http://www.ene.gov.on.ca/envision/ water/sdwa/legislation.htm.

IARC (Iarc Working Group On the Evaluation of the Carcinogenic Risk of Chemicals to Humans), 1978. NNitrosodimethylamine. In: IARC Monographs on the Evaluation of the Carcinogenic Risk of Chemicals to Humans. Some N-Nitroso Compounds. World Health Organization, Switzerland. 17: 125-175.

Jobb D B, Hunsinger R, Meresz O, Taguchi V Y, 1992. A study of the occurrence and inhibition of formation of $\mathrm{N}$-nitrosodimethylamine (NDMA) in the Ohsweken water supply. In: Proceedings of the Fifth National Conference on Drinking Water, Winnipeg, Manitoba, Canada

Mari A, Masami O, Koji K, 2009. A nationwide survey of NDMA in raw and drinking water in Japan. Science of the Total Environment, 407: 3540-3545.

OMOE (Ontario Ministry of the Environment), 2003. Technical Support Document for Ontario Drinking Water Standards, Objectives and Guidelines. http://www.ene.gov.on.ca/envision/gp/4449e01.pdf (revised June, 2006). Ontario, Toronto.

US EPA, 2004. Method 521 determination 465 on of nitrosamines in drinking water by solid phase extraction and capillary column gas chromatography with large volume injection and chemical ionization tandem mass spectrometry (MS/MS). National Exposure Research Laboratory Office of Research and Development, EPA/600/R-05/054.

US EPA, 2006. Unregulated Contaminant Monitoring Rule 2 (UCMR2).

US EPA, 2009. N-Nitrosodimethylamine (CASRN 62-75-9). Integrated Risk Information System (IRIS) as of January. http://www.epa.gov/ncea/iris/subst/0045.htm.

William A M, Jonathan O S, Trussell R R, Richard L V, Lisa A C, David L S, 2003. N-Nirtosodimethylamine (NDMA) as a drinking water contaminant: A review. Environment Engineer Sciences, 20(5): 389- 404.

Zhao Y Y, Jessica M B, Matthew W, Robert C A, Qin F, Steve E H et al., 2008. Formation of N-nitrosamines from eleven disinfection treatments of seven different surface waters. Environmental Science and Technology, 42(13): 4857-4862. 